\title{
Study on the Development Problems and Trend of Scenic Planning
}

\author{
Chen Ding ${ }^{1}$
}

${ }^{1}$ Xi'an International University, Xi'an, Shaanxi, 710077

\section{KEYWORDS: Tourist Attractions, Planning Development, Problem, Trends}

\begin{abstract}
With the rapid development of tourism in recent years, all over the country are conducting tourism resources planning and development of tourist attractions. But in the actual planning and development process, part of the development of tourist attractions, but some problems condition in which many complex reasons. To this end, between the planning and development of tourist attractions existing problems and development trend analysis series, trying to find a solution to the problem, avoid the errors into tourist attractions in the planning and development process.
\end{abstract}

\section{Introduction}

With the recent rapid development of China's tourism industry, the country are vigorously carry out the planning and development of new tourist attractions scenic. Due to blindly follow the lead of some of the new planning tourist attractions have not been rational development, at the same time some tourist areas did not fully consider the actual market demand, excessive, uncontrolled development leading to a series of problems. Thus, the full correct understanding of tourist attractions in the planning and development problems and to find effective solutions, so tourist resort planning and development on the right track towards the path of sustained rapid development of ecological health.

\section{The Tourism Plan Development Problems}

In the current tourist resort planning and development process, there is a pervasive phenomenon of over-exploitation. Some tourist resort developers and business owners affected by the commercial interests of the market, driven by the development of a large number of tourist attractions in the resort area of interest in order to win market economy, the construction of a large number of electrical equipment, hotel housing, communication cables, and other tourism projects to attract the number of visitors. At the same time due to excessive development of tourist attractions due to urbanization, people good fortune attractions gradually increased, prompting Tourist "flavor" fades, tourist attractions not only undermine the ecological environment, but also seriously affected the interest of tourists travel. Due to the temptation of the commercial interests of the market and many tourist attractions developers and business owners often acts recklessly to over-exploitation of scenic spots in the interests of compromise, and in total disregard of scientific development and construction of tourist attractions, normative, often resulting in economic serious losses and waste, can be described as a waste of resources. Further, since the deletion of part of the area of scientific development and construction of normative, does not conform to a certain extent, humane, ecological development and construction, lack of awareness of environmental protection, social responsibility will be ignored, it is likely to cause significant negative to the community influences. 
Scenic individual local development not only heavy weight protection, leading to serious white pollution tourist attractions, scenic scene repeated destruction and other issues. To seek the interests of some local tourist attractions while ignoring environmental protection of resources, often to make some "sacrificing the environment in exchange for economic benefits," the absurd development. Planning and development of tourist attractions will inevitably result in a certain area within the ecological impact of tourism planning and development should therefore be established on the basis of the implementation of protection, so as to ensure that no early complete destruction of environmental resources. Meanwhile, the tourist attractions do what protection is also a behavior, the behavior of protection in the development of operating profit realized on the basis of resort, there is no money to protect what means profit. Similarly, simply development operations at the expense of environmental protection is in vain, so there must be a mutual balance between nature and scenic protected area development, the pattern "Protection - Development - Operations Protection - Development - Operations - protection", this model is constantly circulating, also a two-way, and after the development of operations, balance between development and protection of both is that operating profit funds. In the consciousness of environmental protection between the two and most of the main, a good awareness of environmental protection is the principle of balance between the three.

Each resort has the appearance of a certain humanistic value, whether natural or man-made. Cultural expert is a scenic area of its core values, the cultural connotation of cultural atmosphere can be elegant, simple and can be life customs, representatives of various cultural connotation of the characteristics of various scenic spots. No cultural foundation, cultural background, cultural connotation of the area planning and development, are tourist attractions industry "shabby." Since the resort also has a real cultural, cognitive and cultural value for the level of planning is to determine the important options for development. Tourist attractions such as historic buildings, scenic if the lack of knowledge of history, not only the development of tourist attractions does not embody the historical value of its own, but also may bring social joke. Also in the section are more representative of historical and cultural attractions, we should not blindly use of modern building materials and technology, to fully understand the historical value combined with its scenic and cultural connotations, full of scenic characteristics, in order to achieve "the King can tours, there are bits goods "scenic effect, to meet the tourists the purpose of achieving the development of operational efficiency.

In general, the tourism industry has brought rapid development of the scale of the area planning some extent to the planning and development of future resorts provide regularity, science, rationality and effectiveness instance basis. But for now, just a little place in the pursuit of blind preparation of planning for the realization of the development of the so-called economies of scale to make a dispensable item. Scenic no real meaning at all tourism, waste of resources land use, but also a serious procrastination local tourism economy index. A tourist area planning the ultimate value is reflected in its actual development operations, resort planning some places completely lost the independent development of operational functions, resulting in the resort "abandoned" phenomenon. On China's economic construction sites, tourist attractions planning actually is a serious and rigorous thing, the need for official public bidding. However, in actual operation, tourist attractions developers and operators of the very low threshold, the larger its randomness, the regulatory authority is not enough, non-existent, the resort developer and operator of the owners of the uncertainty difficult to meet the required scientific and resort planning and development, standardization, ecology and so on. Such regulatory planning is neglected, resulting in the 
regulation of resort planning and development of binding enough to resort planning and development drilling unreasonable loopholes.

Is currently planning the development of tourist attractions, there are still many other issues, such as planning by the local geographical conditions, the feasibility is not high; the place is too high, a short time cannot be met; too heavy development investment, financial chain pressure; focus on the form of development, items missing content, and so on. The cause of the problem is not unity, but also complex, and one reason is not formed in one or two days, the solution involves not only a matter of time, money problems, there are many conditions surrounding the problem, in short, all of a sudden not be able to finalize down thing. Yet, for now planning the development of tourist attractions, it is still in the exploration stage and into production, the relevant business units of local government departments have attached great importance to require attention, be rigorous scientific attitude and approach, proper guidance and supervision, and gradually solve the perfect Summing the question stated, to facilitate the planning of the development of tourist attractions in the continuous development of better and faster pace of progress [1].

\section{The Development Trend of the Development of Tourist Attractions Planning}

Traditional tourist resort planning and development approach is relatively simple, usually with Chinese tradition, history, culture and other characteristics to the planning and development of scenic spots, such as temples, Taoist, ancestral town, Memorial Hall. Modern tourism pay more attention to multi-stakeholder involvement, by hotels, restaurants, travel agencies, tour agencies and other tourism-related industries with the proposed reference to achieve planned development of tourist attractions. Based on the cultural characteristics of the tourist attractions, tourist routes, tourist attractions, tourism, housing, tourism and other multi-faceted comprehensive reference time to put forward opinions and suggestions Scenic planning and development feasibility. This type of integrated planning and development of the tourism industry has a market not only in reality, the reference value of the market, but also on the basis of market feasibility, planning the future development of a trend in tourist areas on the body.

Key scientific development to guide the development of tourism planning and co-ordination of all aspects of that relationship, taking into account the actual needs of all parties. Specifically, it is in the actual planning of the development of tourist attractions, infrastructure and overall good tourist attractions, cultural, specialty construction and a variety of construction, overall good tourist attractions in the current and future expansion of the business travel market, and the overall tourist attractions resources within the environmental protection. Adhere to the scientific concept of development, to regulate science Coordinator: scientific development, construction science, scientific development, scientific conservation and scientific principles of sustainable development adhere to the scientific co-ordination. The first is to confirm Scenic environmental planning and development in environmentally protected cycle implementation of scientific premise to make a scientific assessment of the planning and development of tourist attractions, to fully consider the planning and development of tourist attractions environmental impact, combined with environmental protection control measures to guide the planning and development of environmental protection, development and implementation of environmental protection plan to ensure the scenic resources and the environment will not be affected by development planning; second is the relationship between science resource allocation in accordance with the ecological environment, the use of resource-saving control to meet the business travel market and economic efficiency, combining eco-tourism demand for tourist attractions for a reasonable planning and development, in order to achieve the sustainable development of eco-tourism resources and economic use of the 
tourism market. Then adhere to the scientific principles of sustainable development, science and tourist attractions of the estimated market demand and market supply, to establish a market evaluation system of tourism attractions, tourists and reasonable control of tourist attractions, and actively carry out environmental protection scenic resources, tourism resources to ensure ecological environment for sustainable use, and to promote the sustainable development of tourist attractions.

Adhere to the concept of sustainable development is planning to develop tourist attractions normalized current trends and the future. Adhere to the concept of sustainable development in the tourist resort planning and development, creating a better environment for tourism and economic benefits for the tourism market. Tourism environment is the basis for planning and development of scenic spots, tourist attractions economic benefit is an important prerequisite for sustainable development. In general, tourism resources, scenic bright, beautiful ecological environment, profound cultural connotation, there will be a strong attraction in the tourism market, but also the nature of tourist attractions lies. Therefore adhere to the tourist resort planning and development concept of sustainable development can not only provide high-quality travel experience for the market, but also to safeguard the future with a sustainable development of tourism resources and tourism environment. Therefore adhere to the tourist resort planning and development concept of sustainable development can not only provide high-quality travel experience for the market, but also to safeguard the future with a sustainable development of tourism resources and tourism environment. Conventional tourist resort developers or commercial enterprises in pursuit of economic interests, predatory tourism resources planning and development, to ecological tourism area caused the severity of damage; blindly to attract tourists, tourist attractions completely ignored passenger throughput, tourist attractions overload operators, completely ignored scenic resource supply and ecological environment of tolerance, economic benefits to the tourism market and travel experience tremendous negative impact, thereby promoting the loss of the tourism value of tourist attractions, tourist attractions abandoned. Nature tourism commercial market survival of the fittest and therefore makes the concept of sustainable development has been fully utilized, the concept of sustainable development emphasized the harmonious coexistence between man and the environment, not only concerned about the interests of the moment, but also takes into account the interests of the future. Adhere to the planning and development of tourist attractions of the concept of sustainable development, one of the relationship between protection and development are the main focus of sustainability, achieve economies without destroying the environment, protect the ecological environment while achieving economic efficiency. This cycle of sustainable development is the main development trend of the future planning and development of tourist attractions.

\section{REFERENCE:}

[1] Song Chunyan. Tourist Resort Planning And Development Of The Existing Problems And Development Trend [J]. Liaoning Educational Administration Institute, 2009, 12: 108-109.

[2] Renxiu Fen Survey Development of Scenic Spots [J]. Economist, 2011, 02: 288-289.

[3] Song Ran Ran, Fan Guosheng, Chen Jian. Sustainable Development of Ecotourism Planning and Tourism [J]. Sichuan Building, 2011, 01: 22-24.

[4] Bears and Eagles Ecotourism Carrying Capacity Study Progress and Prospects [J]. Economic Geography, 2013, 05: 174-181. 